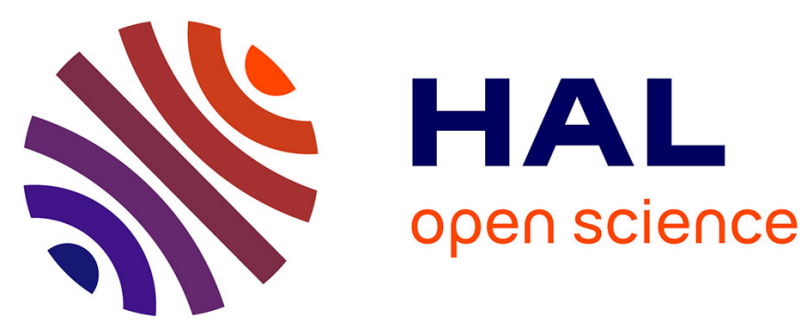

\title{
A one-dimensional metal embedded in salt matrices: Synthesis, modulated crystal structures, electrical conductivity, and chemical bonding of $[\mathrm{PdBi} 6]\left[(\mathrm{Bi}, \mathrm{Sn}) 1-\delta \mathrm{Br} 5-\delta^{\prime}\right]$
}

Bernhard Wahl, Lars Kloo, Michael Ruck

\section{To cite this version:}

Bernhard Wahl, Lars Kloo, Michael Ruck. A one-dimensional metal embedded in salt matrices: Synthesis, modulated crystal structures, electrical conductivity, and chemical bonding of $[\mathrm{PdBi} 6]\left[(\mathrm{Bi}, \mathrm{Sn}) 1-\delta \mathrm{Br} 5-\delta^{\prime}\right]$. Journal of Inorganic and General Chemistry / Zeitschrift für anorganische und allgemeine Chemie, 2009, 635 (12), pp.1979. 10.1002/zaac.200900191 . hal-00501884

\section{HAL Id: hal-00501884 \\ https://hal.science/hal-00501884}

Submitted on 13 Jul 2010

HAL is a multi-disciplinary open access archive for the deposit and dissemination of scientific research documents, whether they are published or not. The documents may come from teaching and research institutions in France or abroad, or from public or private research centers.
L'archive ouverte pluridisciplinaire HAL, est destinée au dépôt et à la diffusion de documents scientifiques de niveau recherche, publiés ou non, émanant des établissements d'enseignement et de recherche français ou étrangers, des laboratoires publics ou privés. 


\section{A one-dimensional metal embedded in salt matrices: Synthesis, modulated crystal structures, electrical conductivity, and chemical bonding of $\left[\mathrm{PdBi}_{6}\right]\left[(\mathrm{Bi}, \mathrm{Sn})_{1-\delta} \mathrm{Br}_{5-\delta^{\prime}}\right]$}

\begin{tabular}{|r|l|}
\hline Journal: & Zeitschrift für Anorganische und Allgemeine Chemie \\
\hline Manuscript ID: & zaac. 200900191.R1 \\
\hline Wiley - Manuscript type: & Article \\
\hline Date Submitted by the \\
Author: & $12-$ May-2009 \\
\hline Complete List of Authors: & $\begin{array}{l}\text { Wahl, Bernhard; Technische Universität Dresden, Fachrichtung } \\
\text { Chemie und Lebensmittelchemie } \\
\text { Kloo, Lars; Royal Institute of Technology, Department of Chemistry } \\
\text { Ruck, Michael; Technische Universität Dresden, Fachrichtung } \\
\text { Chemie und Lebensmittelchemie }\end{array}$ \\
\hline Keywords: & $\begin{array}{l}\text { Bismuth, Confined metals, Metal-salt-hybrids, Modulated crystal } \\
\text { structures, One-dimensional metals }\end{array}$ \\
\hline &
\end{tabular}

\section{(5) SholaroNE \\ Manuscript Central}




\title{
A one-dimensional metal embedded in salt matrices: Synthesis, modulated crystal structures, electrical conductivity, and chemical bonding of ${ }_{\infty}^{1}\left[\mathrm{PdBi}_{6}\right]\left[(\mathrm{Bi}, \mathrm{Sn})_{1-\delta} \mathrm{Br}_{5-\delta},\right]$
}

\author{
Bernhard Wahl, ${ }^{[\mathrm{a}]}$ Lars Kloo, $^{[\mathrm{b}]}$ and Michael Ruck ${ }^{*[a]}$
}

Dedicated to Professor Martin Jansen on the Occasion of his $65^{\text {th }}$ Birthday

Keywords: Bismuth; Confined metals; Metal-salt-hybrids; Modulated crystal structures; One-dimensional metals; Palladium

The metal-rich compounds $\left[\mathrm{PdBi}_{6}\right]\left[(\mathrm{Bi}, \mathrm{Sn})_{1-\delta} \mathrm{Br}_{5-\delta}\right]$ with $\delta_{1}={ }^{2} / 13$, synthesized from $\mathrm{Bi}_{2} \mathrm{Pd}$, $\mathrm{BiBr}_{3}$, and $\mathrm{Sn}$ at $300{ }^{\circ} \mathrm{C}$. The crystal structures contain intermetallic rods 1 [ $\left[\mathrm{Pd} @ \mathrm{Bi}_{2 / 1} \mathrm{Bi}_{8 / 2}\right]^{2.5+}$ embedded in salt-like matrices, which consist of groups of bromido-bismuthate(III)-stannate(II) octahedra $\left[(\mathrm{Bi}, \mathrm{Sn})_{\mathrm{n}} \mathrm{Br}_{4 \mathrm{n}+2}\right]^{\mathrm{m}-}(n=2,3)$ and isolated $\mathrm{Br}^{-}$ions. Metrical incompatibilities of the two subsystems in the crystalline metal-salthybrid result in non-stoichiometry of the salt part associated with complex superstructures. The average structure is described in the orthorhombic space group Pmmm with $a \approx 408 \mathrm{pm}, b \approx 2263 \mathrm{pm}, c$ $\approx 849 \mathrm{pm}$. It feigns statistical distribution of vacancies and orientational disorder of the concatenated octahedra. By choosing the modulation vectors $\mathbf{q}_{\mathbf{i}}={ }^{2} / \mathbf{a}^{*}+1 / 2 \mathbf{b}^{*}+1 / 2 \mathbf{c}^{*}$ with $t_{1}=13$ or $t_{2}=12$, the additional weak reflections of the diffraction patterns are indexed. Ordered structure models are achieved in the $[3+1]$ dimensional superspace group $\operatorname{Pmmm}\left(\alpha^{1 / 2} 2^{1 / 2}\right) 000$. Metallic conductivity along [100], i.e. the direction of the ${ }_{\infty}^{1}\left[\mathrm{Pd} @ \mathrm{Bi}_{2 / 1} \mathrm{Bi}_{8 / 2}\right]^{2.5+}$ rods, was determined for a single-crystal. One-dimensional band structure calculations reveal $\mathrm{Bi} p$-bands crossing the Fermi level for formula charges higher than $2+$. The electron localization indicator (ELI) indicates two-center Bi-Bi bonds as well as multi-center bonds inside the metallic part, while the Bi lone-pairs point towards the non-conducting part of the structure.

\section{Introduction}

Low dimensional metallic systems are of great interest for experimentalists as well as for theoreticians [1]. The dramatic changes in properties by spatial confinement of a three-dimensional electron gas, being described by the concept of the Fermi liquid [2], to only one dimension, where the concept of the Luttinger liquid [3] has to be applied, are still not fully understood. Proposed models for their description and comprehension have to be verified, expanded or modified. A classic among the 1D-metals is the columnar structure of $\mathrm{K}_{2}\left[\mathrm{Pt}(\mathrm{CN})_{4}\right] \mathrm{Cl}_{0.32} \cdot 2.6 \mathrm{H}_{2} \mathrm{O}$, known as Krogmann salt [4]. Maybe the systems examined most extensively are organic materials known as Bechgaard and Fabre salts [5], which under certain conditions represent one-dimensional conductors.

[a] Department of Chemistry and Food Chemistry, Dresden University of Technology, D-01062 Dresden, Germany Fax: +49-351-463-37287 E-mail: michael.ruck@chemie.tu-dresden.de

[b] Department of Chemistry, Royal Institute of Technology, S-10044 Stockholm, Sweden

Supporting information for this article is available on the WWW under http://www.zaac.wiley-vch.de or from the author.
Also several low-dimensional metals based on isolated columns of concatenated metal clusters moved into the focus of research, e.g. chalcogenides $\mathrm{Ta}_{4} M \mathrm{Te}_{4}(M=\mathrm{Si}, \mathrm{Fe}$, Co) [6], Chevrel phases like $\mathrm{Tl}_{2} \mathrm{Mo}_{6} \mathrm{Se}_{6}$ [7], and low-valent Bi- $M(M=\mathrm{Ni}, \mathrm{Rh}, \mathrm{Ir})$ halides [8, 9] and sulfohalides [10]. But still the number of such systems is rather small.

We now succeeded in enlarging the family of onedimensional metals and present herein the crystalline metalsalt-hybrids $\left[\mathrm{PdBi}_{6}\right]\left[(\mathrm{Bi}, \mathrm{Sn})_{1-\delta} \mathrm{Br}_{5-\delta}\right]$. We identified two different commensurately modulated structures, in which metallic rods ${ }_{\infty}^{1}\left[\mathrm{Pd} @ \mathrm{Bi}_{2 / 1} \mathrm{Bi}_{8 / 2}\right]$ are separated by insulating bromido-metallate groups.

\section{Experimental Section}

\section{Synthesis}

Prior to the synthesis Bi powder (99.5\%, Alfa Aesar, treated with hydrogen at $200{ }^{\circ} \mathrm{C}$ to remove oxygen impurities) and $\mathrm{Pd}(99.99 \%$, Degussa) were heated to form the intermetallic phase $\mathrm{Bi}_{2} \mathrm{Pd}$. The title compound then was synthesized with high yields in fused silica ampoules $\left(V \approx 17 \mathrm{~cm}^{3}\right)$ by annealing mixtures (in total about $1 \mathrm{~g}$ ) of $\mathrm{Bi}_{2} \mathrm{Pd}$, Sn $\left(99.9+\%\right.$, Chempur) and $\mathrm{BiBr}_{3}$ (Riedel-de Haën, $99 \%$, sublimated three times from $220{ }^{\circ} \mathrm{C}$ to ambient temperature) in the approximate ratios $\mathrm{Pd}: \mathrm{Bi}: \mathrm{Sn}: \mathrm{Br}=1:(6.5$ to 6.8$):(0.3$ to $0.08): 5$ at $300^{\circ} \mathrm{C}$ for three weeks. At least traces of Sn have to be present for the formation of the product. Several efforts to 
synthesize the hypothetical tin-free ternary compound using equal conditions always failed and resulted in $\mathrm{Bi}_{14} \mathrm{PdBr}_{16}$ [11] as the main product.

The semi-quantitative energy dispersive X-ray analysis (EDX) of previously identified single-crystals was performed on a scanning electron microscope (type CamScan CS 44). All four elements (including significant traces of $\mathrm{Sn}$ ), but no impurities caused by other elements could be detected. The determined ratio at an acceleration voltage of $10 \mathrm{keV}$ using 300000 counts for the evaluation resulted in the element ratio $\mathrm{Bi}: \mathrm{Sn}: \mathrm{Pd}: \mathrm{Br}=56: 2: 8$ $: 33$. This is in good agreement with the composition derived from the X-ray structure determination of the modulation variant (1) (52 : $2: 8: 38)$. An additionally recorded spectrum at $20 \mathrm{keV}$ with 300000 counts resulted in a $\mathrm{Bi}: \mathrm{Br}$ ratio of $53: 38$.

The temperature dependence of the ohmic resistance of a needleshaped single-crystal was measured by a four point dc method using a PPMS device (Quantum Design).

\section{X-ray crystal-structure determination}

The diffraction data were collected on an imaging plate diffraction system IPDS-II (Stoe). Based on an optimized crystal description numerical absorption corrections were applied [12]. The structures were refined against $F_{\mathrm{o}}{ }^{2}$ with the SHELX97 [13] (average structures) and the JANA2000 program packages [14]. The diffraction patterns of several single-crystals obtained with a precession camera (imaging plate, Zr-filtered Mo radiation) point to the Laue symmetry $\mathrm{mmm}$. The strongest reflections allow indexing with an orthorhombic cell and cell parameters $a \approx 410$ $\mathrm{pm}, b \approx 1130 \mathrm{pm}, c \approx 850 \mathrm{pm}$. However, the diffraction pattern shows, beside rows of the main reflections, additional weak but sharp superstructure reflections (Figure 1). According to the diffraction pattern, the crystal structure can be interpreted either as a commensurately $2 \mathrm{D}$-modulated structure with lattice parameters of the subcell $\left(\mathbf{q}_{\mathbf{a}} \approx 2 \mathbf{a} * / t-\mathbf{b} * / 4+\mathbf{c} * / 2\right.$ and $\mathbf{q}_{\mathbf{b}} \approx-2 \mathbf{a} * / t+\mathbf{b} * / 4+$ $\mathbf{c}^{*} / 2, t=12,13$ ) or, as indicated in Figure 1, as a commensurately 1D-modulated superstructure of the subcell in conjunction with a doubling of the lattice vector $\mathbf{b}$. The refinement of the latter proved to be successful. Special reflection conditions have been observed neither for the main reflections nor for the satellites.

Figure 1. Schematic diffraction pattern of the layers $h k 0 m, h k^{1} / 2 m$, $h 0 l m$ and $h^{1 / 2} l m$ including the chosen q-vector. Main reflections are represented in black, $1^{\text {st }}$ order satellites in dark gray, and $2^{\text {nd }}$ order satellites in light gray. Empty circles in intermediate layers correspond to the position of main reflections.

Modulation variant (1): $\left[\mathrm{PdBi}_{6}\right]\left(\mathrm{Bi}_{0.60(1)} \mathrm{Sn}_{0.24(1)} \mathrm{Br}_{4}\right) \mathrm{Br}_{0.80(1)} ; T=$ $293(2) \mathrm{K}, 2 \theta_{\max }=58.5^{\circ}, \lambda\left(\mathrm{Mo} K_{\alpha}\right)=71.073 \mathrm{pm}, a=407.37(2), b=$ 2262.37(14), $c=849.22(6) \mathrm{pm}, V=782.66(8) \cdot 10^{6} \mathrm{pm}^{3}, T_{\max } / T_{\min }=$ $0.460 / 0.022, \mu\left(\mathrm{Mo}_{\alpha}\right)=87.4 \mathrm{~mm}^{-1}, \rho_{\text {calc }}=8.060 \mathrm{~g} \mathrm{~cm}^{-3}$.

Average structure: orthorhombic, space group Pmmm (No. 47); $R_{1}$ $\left(1074 I_{\mathrm{o}}>2 \sigma\left(I_{\mathrm{o}}\right)\right)=0.039, w R_{2}($ all data $)=0.086 ; G o o F=1.07$ for 1304 unique reflections and 69 parameters; min./max. residual electron density $+1.97 /-2.38 \mathrm{e} /\left(10^{6} \mathrm{pm}^{3}\right)$.

Modulated structure: orthorhombic, superspace group $\operatorname{Pmmm}\left(\alpha^{1 / 2} 2^{1 / 2}\right) 000$ (No. 47.6) with $\mathbf{q}_{1}=2 / 13 \mathbf{a}^{*}+1 / 2 \mathbf{b}^{*}+1 / 2 \mathbf{c}^{*}$ (resp. $\operatorname{Xmmm}\left(\alpha^{1 / 2} 2^{1 / 2}\right) 000$ with $\left.\mathbf{q}_{1}{ }^{\prime}={ }^{2} / 13 \mathbf{a}^{*}\right)$. Main reflections $R_{1}\left(1029 I_{\mathrm{o}}\right.$ $\left.>3 \sigma\left(I_{0}\right)\right)=0.040, w R_{2}$ (all data) $=0.079 ; 1^{\text {st }}$ order satellites $R_{1}$ $\left(1493 I_{\mathrm{o}}>3 \sigma\left(I_{\mathrm{o}}\right)\right)=0.082, w R_{2}$ (all data) $=0.119 ; 2^{\text {nd }}$ order satellites $R_{1}\left(678 I_{\mathrm{o}}>3 \sigma\left(I_{\mathrm{o}}\right)\right)=0.246, w R_{2}($ all data $)=0.425 ; 99$ parameters, 2 restrictions.
Modulation variant (2): $\left[\mathrm{PdBi}_{6}\right]\left(\mathrm{Bi}_{0.69(1)} \mathrm{Sn}_{0.14(1)} \mathrm{Br}_{4}\right) \mathrm{Br}_{0.83(1)} ; T=$ $293(2) \mathrm{K}, 2 \theta_{\max }=58.5^{\circ}, \lambda\left(\mathrm{MoK}_{\alpha}\right)=71.073 \mathrm{pm}, a=408.28(1), b=$ 2264.93(8), $c=849.69(4) \mathrm{pm}, V=785.73(5) \cdot 10^{6} \mathrm{pm}^{3}, T_{\max } / T_{\min }=$ $0.133 / 0.003$, absorption coefficient $\mu\left(\mathrm{Mo} K_{\alpha}\right)=87.9 \mathrm{~mm}^{-1}, \rho_{\text {calc }}=$ $8.061 \mathrm{~g} \mathrm{~cm}^{-3}$.

Average structure: orthorhombic, space group Pmmm (No. 47); $R_{1}$ $\left(1017 I_{\mathrm{o}}>2 \sigma\left(I_{\mathrm{o}}\right)\right)=0.060, w R_{2}$ (all data) $=0.133 ; \mathrm{GooF}=1.48$ for 1308 unique reflections and 69 parameters; min./max. residual electron density $+2.28 /-3.48 \mathrm{e} /\left(10^{6} \mathrm{pm}^{3}\right)$.

Modulated structure: orthorhombic, superspace group $\operatorname{Pmmm}\left(\alpha^{1 / 2} 2^{1 / 2}\right) 000$ (No. 47.6) with $\mathbf{q}_{2}={ }^{2} / 12 \mathbf{a}^{*}+1 / 2 \mathbf{b}^{*}+1 / 2 \mathbf{c}^{*}$ (resp.

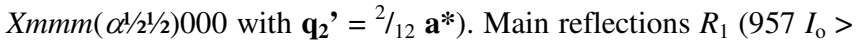
$\left.3 \sigma\left(I_{0}\right)\right)=0.061, w R_{2}($ all data $)=0.094 ; 1^{\text {st }}$ order satellites $R_{1}(1238$ $\left.I_{\mathrm{o}}>3 \sigma\left(I_{\mathrm{o}}\right)\right)=0.086, w R_{2}($ all data $)=0.118 ; 2^{\text {nd }}$ order satellites $R_{1}$ $\left(496 I_{\mathrm{o}}>3 \sigma\left(I_{\mathrm{o}}\right)\right)=0.189, w R_{2}($ all data $)=0.358 ; 99$ parameters, 2 restrictions.

Supporting Information on the results of the refinements of the modulated crystal structures is available online (see footnote on the first page of this article). Further data, in the form of a CIF, have been deposited with the Fachinformationszentrum Karlsruhe, D76344 Eggenstein-Leopoldshafen, Germany (E-mail address: crysdata@fiz-karlsruhe.de), as supplementary material no. CSD420562 (1) or CSD- 420563 (2), and can be obtained by contacting the FIZ quoting the article details and the CSD number. Graphics of the structure were prepared using the program Diamond [15].

\section{Quantum-chemical calculations}

$\mathrm{Ab}$ initio hybrid-DFT band structure calculations were carried out using the program Crystal06 [16] and the B3LYP functional [17]. Isolated intermetallic rods ${ }_{\infty}^{1}\left[\mathrm{PdBi}_{2 / 1} \mathrm{Bi}_{8 / 2}\right]^{\mathrm{m}+}$ (rod group $\mathrm{mmm}$, no. 20) with charges of $m=2,2.5$, or 3 were chosen as approximants for the chemical bonding within the crystal structure. The atomic coordinates of the crystal structure were used. For Pd and Bi the basis sets given in literature $[18,19]$ were slightly modified. The core electrons were replaced by the energy consistent effective core potentials ECPMWB78 [18] for Bi and ECPMWB28 for Pd [20].

Since quantum chemical calculations of structures with broken charges are not possible, the charge of $2.5+$ per repetition unit was emulated by a rod $1_{\infty}^{1}\left[\mathrm{PdBi}_{2 / 1} \mathrm{Bi}_{8 / 2}\right]_{2}^{5+}$ with lattice parameter $2 a$. For testing measures the models with integer charges were calculated in this super cell as well. In these cases, only the number of bands but not their shape differed. Calculations based on three dimensional approximants failed due to convergence problems.

In addition, the atomic parameters of the cluster tetramer $\left[\mathrm{Pd}_{4} \mathrm{Bi}_{28}\right]^{8+}\left(D_{2 \mathrm{~h}}\right.$ symmetry $)$ were optimized applying cc-PVDZbasis sets [21,22] and the effective core potentials ECPMDF60 for Bi [21] und ECPMDF28 for Pd [22]. The molecular B3LYP hybrid-DFT calculations were carried out using the Gaussian03 program package [23]. The interatomic distances $a$ to $d$ within the ${ }_{\infty}^{1}\left[\mathrm{PdBi}_{2 / 1} \mathrm{Bi}_{8 / 2}\right]$ rods (Figure 3 ) were reproduced quite well. Only the distance $d$ in the cap was somewhat shorter. Using the obtained wave functions the electron localization indicator (ELI-D) for triplet coupled electrons [24] was calculated with the program dgrid [25]. The surfaces were plotted with the program Molekel 4.3 [26]. 


\section{Results and Discussion}

The new metal-rich compounds $\left[\mathrm{PdBi}_{6}\right]\left[(\mathrm{Bi}, \mathrm{Sn})_{1-\delta} \mathrm{Br}_{5-\delta}\right]$ have been synthesized from $\mathrm{Bi}_{2} \mathrm{Pd}, \mathrm{BiBr}_{3}$, and $\mathrm{Sn}$ at $300{ }^{\circ} \mathrm{C}$. The shiny black, needle-shaped crystals are insensitive to air and decompose under equilibrium pressure at 602(5) $\mathrm{K}$. Crystals of two slightly different compositions and structures have been investigated. Type (1) has the composition $\left[\mathrm{PdBi}_{6}\right]\left[\mathrm{Bi}_{0.60(1)} \mathrm{Sn}_{0.24(1)} \mathrm{Br}_{4.80(1)}\right]\left(\delta_{1}=0.16, \delta_{1}=\right.$ 0.20), while type (2) has the sum formula $\left[\mathrm{PdBi}_{6}\right]\left[\mathrm{Bi}_{0.69(1)} \mathrm{Sn}_{0.14(1)} \mathrm{Br}_{4.83(1)}\right]\left(\delta_{2}=0.17, \delta_{2}=0.17\right)$. The orthorhombic structures (Figure 2) are composed of metallic rods $1\left[\mathrm{Pd} @ \mathrm{Bi}_{2 / 1} \mathrm{Bi}_{8 / 2}\right]^{2.5+}$ and salt-like matrices, which consist of groups of bromido-bismuthate(III)-stannate(II) octahedra $\left[(\mathrm{Bi}, \mathrm{Sn})_{\mathrm{n}} \mathrm{Br}_{4 \mathrm{n}+2}\right]^{\mathrm{m}-}(n=2,3)$ and isolated $\mathrm{Br}^{-}$ions. Metrical incompatibilities of the two subsystems in the metal salt hybrid result in non-stoichiometry of the salt-like part associated with complex ordering schemes.

Figure 2. Average structure of $\left[\mathrm{PdBi}_{6}\right]\left[(\mathrm{Bi}, \mathrm{Sn})_{1-\delta} \mathrm{Br}_{5-\delta}\right]$. The displacement ellipsoids represent $90 \%$ probability at $293(2) \mathrm{K}$. As in the following figures. Pd atoms are represented in black, Bi atoms in dark gray, and $\mathrm{Br}$ atoms medium gray.

The metallic rods $1 \quad\left[\mathrm{Pd} @ \mathrm{Bi}_{2 / 1} \mathrm{Bi}_{8 / 2}\right]^{2.5+}$ consist of condensed $\left[\mathrm{Pd} @ \mathrm{Bi}_{10}\right]^{2.5+}$ clusters, in which a $\mathrm{Pd}$ atom centers a bi-capped cuboid of $\mathrm{Bi}$ atoms. All $\mathrm{Bi}-\mathrm{Pd}$ distances fall into the narrow range of 305 to $310 \mathrm{pm}$ and are only $2 \%$ longer than in the isolated clusters $\left[\mathrm{Pd} @ \mathrm{Bi}_{10}\right]^{4+}(297$ to 302 pm) [10]. However, the shapes of the $\mathrm{Bi}_{10}$ polyhedra differ considerably. In the pentagonal antiprism $\left[\mathrm{Pd} @ \mathrm{Bi}_{10}\right]^{4+}$, known from $\mathrm{Bi}_{14} \mathrm{PdBr}_{16}$ and similar compounds [10], the $\mathrm{Bi}-\mathrm{Bi}$ distances are almost equal $(315 \pm 3 \mathrm{pm})$ in accordance with the multi-center bonding found. In the present case a pronounced differentiation of $\mathrm{Bi}-\mathrm{Bi}$ bonds is observed. While the $\mathrm{Bi}-\mathrm{Bi}$ distance denoted $b$ in Figure 3 (311 pm) falls into the range typical for multi-center bonds, the short $\mathrm{Bi}-\mathrm{Bi}$ distance $a(302.5 \mathrm{pm})$ corresponds to the length of a polarized $\mathrm{Bi}-\mathrm{Bi}$ single-bond (e.g. $302 \mathrm{pm}$ in $\mathrm{BiBr}=$ $\mathrm{Bi}^{0} \mathrm{Bi}^{\mathrm{II}} \mathrm{Br}_{4 / 2}$ [27]).

Figure 3. Two projections of the ${ }_{\infty}^{1}\left[\mathrm{Pd} @ \mathrm{Bi}_{2 / 1} \mathrm{Bi}_{8 / 2}\right]$ rods. The interatomic distances are $a=302.5(5) \mathrm{pm}, b=311.5(5) \mathrm{pm}, c=$ $355(1) \mathrm{pm}$, and $d=408(1) \mathrm{pm}$. The standard deviations given in parentheses are average values.

There is a striking structural similarity to the structures of the 1D-metals $\mathrm{Bi}_{7-\delta} \mathrm{Ni}_{2} \mathrm{Br}_{5}$ and $\mathrm{Bi}_{7-\delta} \mathrm{Ni}_{2} \mathrm{Br}_{5-2 \delta}$ [8], which contain metallic rods $1_{\infty}^{1}\left[\mathrm{Ni} @ \mathrm{Bi}_{1 / 1} \mathrm{Bi}_{6 / 3}\right]^{\mathrm{y}+}$ separated by nonconducting $\left[\mathrm{Bi}_{\mathrm{n}} \mathrm{Br}_{4 \mathrm{n}+2}\right]^{\mathrm{m}-\mathrm{T}}$ groups and $\mathrm{Br}^{-}$ions. Essential aspects of the crystal chemistry of the bromide-bismuthate part of the structure that are also valid for the underlying case have been discussed there. Since the metallic fragments in $\mathrm{Bi}_{7-\delta} \mathrm{Ni}_{2} \mathrm{Br}_{5(-2 \delta)}$ are known from $\mathrm{Bi}_{3} \mathrm{Ni}$ [28], the corresponding subbromides have been interpreted as oxidation products of the intermetallic phase $[8,29]$. Yet the $1\left[\left(\mathrm{Pd} @ \mathrm{Bi}_{2 / 1} \mathrm{Bi}_{8 / 2}\right)\right]$ rods cannot be derived from an intermetallic $\mathrm{Pd}-\mathrm{Bi}$ phase, since the compound with the largest portion of bismuth is $\mathrm{Bi}_{2} \mathrm{Pd}[30]$, not " $\mathrm{Bi}_{6} \mathrm{Pd}^{2}$.

The first step in the structure analysis of the salt-like part resulted in the average structure, which is based only on the main reflections (Pmmm, $a=407.37(2), b=2262.37(14), c$ $=849.22(6) \mathrm{pm}$ for (1)). Here the bromido-bismuthate(III)-

stannate(II) groups appear as infinite strands of trans-edgesharing $\left[(\mathrm{Bi}, \mathrm{Sn}) \mathrm{Br}_{2 / 1} \mathrm{Br}_{4 / 2}\right]$ octahedra. A local $4_{2}$ screw axis maps two orientations on each other (Figure 4), and the occupancies of the metal atom as well as of the isolated $\mathrm{Br} 1$ atom are diminish. Additionally, several displacement ellipsoids are elongated indicating the superposition of varying atom positions.

Figure 4. Deconvolution of the disorder in the bromidometallate part of the average structure (center) into two differently oriented ${ }_{\infty}^{1}\left[\mathrm{MBr}_{2 / 1} \mathrm{Br}_{4 / 2}\right]$ chains (left, right), that can be mapped on each other by a local $4_{2}$ screw rotation along [100].

Weak superstructure reflections in the diffraction patterns of the single-crystals were indexed using commensurate modulation vectors $\mathbf{q}_{\mathbf{i}}={ }^{2} / \mathbf{a}^{*}+1 / 2 \mathbf{b}^{*}+1 / 2 \mathbf{c}^{*}$ with $t_{1}=13$ for (1) and $t_{2}=12$ for (2). Based on crystal chemical considerations structure models were developed for ordered superstructures with $\mathbf{a}^{\prime}=t \mathbf{a}, \mathbf{b}^{\prime}=2 \mathbf{b}$, and $\mathbf{c}^{\prime}=2 \mathbf{c}$ in space group Pmmm. For their refinement descriptions in the [3+1]dimensional superspace group $\operatorname{Pmmm}\left(\alpha^{1 / 2} \frac{1}{2} / 2\right) 000$ were chosen.

For (1) a section of the anionic part of the crystal structure is given in Figure 5. In a period of $13 \mathbf{a}$, there are three triples of octahedra $\left[(\mathrm{Bi}, \mathrm{Sn})_{3} \mathrm{Br}_{14}\right]$ and one pair of octahedra $\left[(\mathrm{Bi}, \mathrm{Sn})_{2} \mathrm{Br}_{10}\right]$ with alternating orientations $(\mathrm{A})$ and $(\mathrm{B})$. Hence 11 of 13 metal sites are occupied, corresponding to $\delta_{1}$ $=2 / 13$ as well as the component of the modulation vector along $\mathbf{a}^{*}$. In $\mathbf{b}$ direction, the position of the isolated bromine atom $\mathrm{Br} 1$ remains unoccupied between two strands of orientation (B), i.e. $\delta{ }^{\prime}{ }_{1}=5 / 26=5 / 4 \delta_{1}$. For compound (2), 10 of 12 metal sites are occupied, corresponding to $\delta_{2}=2 / 12$, and the occupation of $\mathrm{Br} 1$ is reduced by $\delta_{2}^{\prime}{ }_{2}={ }^{2} / 12=\delta_{2}$.

Figure 5. The ordered anionic structure of $\left[\mathrm{PdBi}_{6}\right]\left[(\mathrm{Bi}, \mathrm{Sn})_{1-\delta} \mathrm{Br}_{5-\delta^{\circ}}\right]$ of the modulation variant (1) in the supercell with $\mathbf{a}=13 \mathbf{a}$ and $\mathbf{b}$, $=2 \mathbf{b}$ and $\mathbf{c}^{\prime}=2 \mathbf{c}$ (space group Pmmm). The upper right side represents a section of the modulated structure around $x=0$. In the boxes, the lengths and the orientations of the concatenated octahedra are indicated. Below the layer at $z=0$, and on the left hand side the layer at $y=1 / 8$ are shown.

In general, the Fourier sections $\left(F_{\mathrm{o}}\right)$ are in a good agreement with the model developed. As an example, the modulation of (1) along [010] is shown in Figure 6. There, only the central atoms of the octahedra with $x_{1}=0.5$, namely $\mathrm{Bi} 3 \mathrm{~B} / \mathrm{Sn} 3 \mathrm{~B}$, appear for certain $x_{4}$ values. The modulations of the atoms $\mathrm{Br} 2$ and $\mathrm{Br} 3$ follow the occupation of the metal sites. The atom $\mathrm{Br} 2 \mathrm{~B}$ moves towards the position of $\mathrm{Br} 1$, when it is void, resulting in a $[5+1]$ coordination of $\mathrm{Bi} 3 \mathrm{~B} / \mathrm{Sn} 3 \mathrm{~B}$. While $\mathrm{Br} 1$ is surrounded by strands of the same orientation, Br11 acts as a buffer between differently orientated strands of octahedra.

Figure 6. The electron density distributions around the atoms $M 3 B$ in $\mathbf{x}_{\mathbf{2}}-\mathbf{x}_{\mathbf{4}}$ of the modulation variant (1) derived from the diffraction pattern including the superstructure reflections. The contour lines symbolize steps within $20 \mathrm{e}^{-} / 10^{6} \mathrm{pm}^{3}$. The bold lines represent the fit of the atomic positions according to the introduced discontinuous and continuous functions. This section underlines the differences in the ordering of the isolated bromine atoms $\mathrm{Br} 1$ and $\mathrm{Br} 11$.

Despite the different q-vectors and the small differences in the anionic substructures, the nominal charge of the metallic rods amounts to +2.50 (2) per formula unit in both variants. Consequently, the ratio $\mathrm{Bi} / \mathrm{Sn}$ and the deficiencies $\delta$ and $\delta$ ' 
seem to be dependent parameters. The proper charge for the structure part $\left[(\mathrm{Bi}, \mathrm{Sn})_{1-\delta} \mathrm{Br}_{5-\delta^{\prime}}\right]$ is met in

(a) the tin-free limit with the boundaries $\left[\mathrm{Bi}_{0.5} \mathrm{Br}_{4.0}\right]^{2.5-}$, i.e. $\delta=1 / 2$ and $\delta^{\prime}=1$, $\left[\mathrm{Bi}_{0.833} \mathrm{Br}_{5.0}\right]^{2.5-}$, i.e. $\delta={ }^{1} / 6$ and $\delta,=0$,

(b) the "bismuth-free" limit with the boundaries $\left[\mathrm{Sn}_{0.75} \mathrm{Br}_{4.0}\right]^{2.5-}$, i.e. $\delta=1 / 4$ and $\delta^{\prime}=1$,
$\left[\mathrm{Sn}_{1.0} \mathrm{Br}_{4.5}\right]^{2.5-}$, i.e. $\delta=0$ and $\delta^{\prime}=1 / 2$.

In practice, a mixed occupancy can hardly be avoided in the presence of tin. On the other hand, we did not succeed in synthesizing a tin-free compound. Apparently, the mixed site occupancy in the concatenated octahedra is necessary to meet the optimum charge as well as the complex metrical and packing requirements.

In order to rationalize the chemical bonding and the physical properties of the title compounds, quantum chemical calculations were performed. Since the intermetallic part of the structure is almost unaffected by the modulation and a realistic model for the anionic part would demand rather large approximants, calculations were carried out for isolated 1 [ $\left.\mathrm{Pd} @ \mathrm{Bi}_{2 / 1} \mathrm{Bi}_{8 / 2}\right]^{\mathrm{m}+}$ rods with different charges $m=2,2.5,3$. The three one-dimensional band structures are almost identical, while the Fermi level is shifted (Figure 7). The bands at the Fermi level are strongly dominated by $p-p$ interactions of Bi. In case of $m=2$, the Fermi level falls into the small band gap. The valence electrons are localized and the rods should be semiconducting. On further oxidation, the Fermi level is lowered and the rods become metallic. The prediction of metallic behavior for $m=2.5$ is confirmed by conductivity measurements on an oriented single-crystal of $\left[\mathrm{PdBi}_{6}\right]\left[(\mathrm{Bi}, \mathrm{Sn})_{1-\delta} \mathrm{Br}_{5-\delta}\right]$ (Figure 8). These results together with the analogy to $\mathrm{Bi}_{7-\delta} \mathrm{Ni}_{2} \mathrm{Br}_{5}$ and $\mathrm{Bi}_{7-\delta} \mathrm{Ni}_{2} \mathrm{Br}_{5-2 \delta}$ [8] encourages us to consider $\left[\mathrm{PdBi}_{6}\right]\left[(\mathrm{Bi}, \mathrm{Sn})_{1-\delta} \mathrm{Br}_{5-\delta},\right]$ as a onedimensional metal along the [100] direction.

Figure 7. One-dimensional band structures of differently charged ${ }_{\infty}\left[\mathrm{Pd} @ \mathrm{Bi}_{2 / 1} \mathrm{Bi}_{8 / 2}\right]^{m+}$ rods.

Figure 8. Temperature dependence of the electric resistance along [100] of a single crystal of $\left[\mathrm{PdBi}_{6}\right]\left[(\mathrm{Bi}, \mathrm{Sn})_{1-\delta} \mathrm{Br}_{5-\delta}\right]$.

A description of chemical bonding in real space can be obtained from the electron localization indicator (ELI-D) of a cluster tetramer $\left[\mathrm{Pd}_{4} \mathrm{Bi}_{28}\right]^{8+}$, see Figure 9. Attractors between $\mathrm{Bi}$ and $\mathrm{Pd}$ are not visible, indicating either highly delocalized multi-center bonds or, in analogy to the pentagonal antiprismatic cluster $\left[\mathrm{Pd} @ \mathrm{Bi}_{10}\right]^{4+}[11,31]$, only weak interactions between the central $\mathrm{Pd}^{0}$ atom $\left(s^{0} d^{10}\right.$ configuration) and the surrounding $\mathrm{Bi}$ shell. The attractors of the ELI-D nicely identify the covalent single bonds between $\mathrm{Bi}$ atoms along the short edges of the cubes (cf. distance $a$ in Figure 3) and multi-center bonds in the triangular faces of the $\mathrm{Bi}_{5}{ }^{+}$caps. Similarly to other intermetallic phases of bismuth [32] and to bismuth clusters [33], the monosynaptic Bi "lone pair" attractors are situated outside the polyhedra and point towards the non-conducting part of the structures. Combined into a simple picture, the 16 electrons in $\mathrm{Bi} 6 p$-orbitals per $\left[\mathrm{Pd} @ \mathrm{Bi}_{2 / 1} \mathrm{Bi}_{8 / 2}\right]^{2+}$ unit are used for ${ }^{4} / 2 \mathrm{Bi}-\mathrm{Bi}(2 \mathrm{c}, 2 \mathrm{e})$-bonds and $(5 \mathrm{c}, 6 \mathrm{e})$-bonds in the two $\mathrm{Bi}_{5}{ }^{+}$ caps. In the infinite rod, the latter molecular orbitals form the bands close to the Fermi level. The almost non-bonding states in the upper half of the highest bonding band are emptied in the oxidation to $1\left[\mathrm{Pd} @ \mathrm{Bi}_{2 / 1} \mathrm{Bi}_{8 / 2}\right]^{2.5+}$.

Figure 9. Two views of the ELI-D $(\eta=1.44)$ of an optimized cluster tetramer $\left[\mathrm{Pd}_{4} \mathrm{Bi}_{28}\right]^{8+}$. The attractors between $\mathrm{Bi}$ atoms can be interpreted as $(2 \mathrm{c}, 2 \mathrm{e})$-bonds on the short edges of the cube and $(5 \mathrm{c}, 6 \mathrm{e})$-bonds in the $\mathrm{Bi}_{5}{ }^{+}$caps .

Figure 10. Scheme of the interactions between $\mathrm{Bi} p$-orbitals in the [Pd@ $\left.\mathrm{Bi}_{2 / 1} \mathrm{Bi}_{8 / 2}\right]^{2+}$ polyhedron. Left: $(2 \mathrm{c}, 2 \mathrm{e})$ bonds along the four short edges of the cube, and empty $p_{z}$-orbitals of $\mathrm{Bi}^{+}$in the apical positions. Right: Top view of a $\mathrm{Bi}_{5}{ }^{+}$cap with six $p_{\mathrm{x}}$ and $p_{\mathrm{y}}$ orbitals, each filled with one electron, that form the $(5 \mathrm{c}, 6 \mathrm{e})$ bond.

\section{Conclusions}

The compounds $\left[\mathrm{PdBi}_{6}\right]\left[(\mathrm{Bi}, \mathrm{Sn})_{1-\delta} \mathrm{Br}_{5-\delta}\right]$ can be regarded as crystalline hybrids of a quasi-one-dimensional metal and a non-conducting salt. They are examples of a chemical confinement of metals and may help to explore the field between the archetypes of covalent and metallic bonding. Besides their value for fundamental research they might be useful for the evaluation of metallic conductivity in electronic devices at the lower end of the nano scale. Beyond this, the inherent differences in chemical bonding and properties could be exploited in order to isolate the metallic nano rods and to integrate them into new hybrid materials or devices.

\section{Acknowledgments}

We thank Dr. E. Langer for the EDX-measurements, Dr. W. Schnelle and Dr. T. P. Papageorgiou for the measurement of the physical properties and $M$. Erbe for experimental assistance. This work was supported by the Deutsche Forschungsgemeinschaft.

[1] a) T. Giamarchi, Chem. Rev. 2004, 104, 5037; b) J. Voit, Rep. Prog. Phys. 1994, 57, 977.

[2] L. D. Landau Sov. Phys. JETP 1957, 3, 920.

[3] J. M. Luttinger, J. Math. Phys. 1963, 4, 1154.

[4] a) K. Krogmann, Angew. Chem. 1969, 81, 10; .Angew. Chem. Int. Ed. Engl. 1969, 8, 35; b) H. Wagner, H. P. Geserich, R. V. Baltz, K. Krogmann, Solid State Commun. 1973, 13, 659.

[5] D. Jérome, Chem. Rev. 2004, 104, 5565.

[6] a) J. Li, R. Hoffmann, M. E. Badding, F. J. DiSalvo, Inorg. Chem. 1990, 29, 3943; b) M. E. Badding, F. J. DiSalvo, Inorg. Chem. 1990, 29, 3952; c) K. Ahn, T. Hughbanks, K. D. D. Rathnayaka, D. G. Naugle, Chem. Mater. 1994, 6, 418; d) J. Neuhausen, E. W. Finekh, W. Tremel, Chem. Ber. 1995, $128,569$.

[7] M. Potel, R. Chevrel, M. Sergent, Acta Crystallogr. 1980, $B 36,1545$.

[8] a) B. Wahl, Th. Doert, T. Söhnel, M. Ruck, Z. Anorg. Allg. Chem. 2005, 631, 457; b) B. Wahl, M. Ruck, Acta Crystallogr. $B$, submitted.

[9] a) M. Ruck, Z. Anorg. Allg. Chem. 1995, 621, 2034; b) M. Ruck, Z. Anorg. Allg. Chem. 1997, 623, 243; c) M. Ruck, Z. Anorg. Allg. Chem. 1999, 625, 453; d) M. Ruck, R. M. Heich, Z. Anorg. Allg. Chem. 2000, 626, 2449.

[10] a) A. I. Baranov, L. Kloo, A. V. Olenev, B. A. Popovkin, A. I. Romanenko, A. V. Shevelkov, J. Am. Chem. Soc. 2001, 123 , 12375; b) A. I. Baranov, L. Kloo, A. V. Olenev, B. A. Popovkin, A. I. Romanenko, Inorg. Chem. 2003, 42, 3989. 
[11] M. Ruck, V. Dubenskyy, T. Söhnel, Angew. Chem. 2003, 115, 3086; Angew. Chem. Int. Ed. 2003, 42, 2978.

[12] a) X-RED32, Data Reduction Program, Version 1.01, Stoe \& Cie GmbH, Darmstadt 2001; b) X-SHAPE, Crystal Optimisation for Numerical Absorption Correction Program, Version 1.06, Stoe \& Cie GmbH, Darmstadt 1999.

[13] a) G. M. Sheldrick, SHELX97, Programs for crystal structure determination, Univ. of Göttingen, 1997; b) G. M. Sheldrick, Acta Crystallogr. 2008, A64, 112.

[14] a) V. Petř́ček, M. Dušek, L. Palatinus, Jana2000, the crystallographic computing system. Institute of Physics, Praha, Czech Republic, 2000; b) V. Petříček, V., A. van der Lee, M. Evain, Acta Crystallogr. 1995, A51, 529; c) L. Palatinus, G. Chapuis, J. Appl. Crystallogr. 2007, 40, 786.

[15] K. Brandenburg, Diamond 3.1f, Crystal and Molecular Structure Visualization, Crystal Impact GbR, Bonn, Germany, 2008.

[16] R. Dovesi, V. R. Saunders, C. Roetti, R. Orlando, C. M. Zicovich-Wilson, F. Pascale F, B. Civalleri, K. Doll, N. M. Harrison, I. J. Bush, Ph. D'Arco, M. Llunell, program Crystal 06, Turin, Italy, 2006.

[17] a) A. D. Becke, J. Chem. Phys. 1993, 98, 5648; b) C. T. Lee, W. T. Yang, R. G. Parr, Phys. Rev. B 1988, 37, 785.

[18] W. Küchle, M. Dolg, H. Stoll, H. Preuss, Mol. Phys. 1991, 74, 1245.

[19] J. M. L. Martin, A. Sundermann, J. Chem. Phys. 2001, 114, 3408.

[20] D. Andrae, U. Häussermann, M. Dolg, H. Stoll, H. Preuss, Theor. Chim. Acta 1990, 77, 123.

[21] B. Metz, H. Stoll, M. Dolg, J. Chem. Phys. 2000, 113, 2563.

[22] K. A. Peterson, D. Figgen, M. Dolg, H. Stoll, J. Chem. Phys. 2007, 126, 124101.

[23] Gaussian 03, Revision C.02, M. J. Frisch, G. W. Trucks, H. B. Schlegel, G. E. Scuseria, M. A. Robb, J. R. Cheeseman, J. A. Montgomery, Jr., T. Vreven, K. N. Kudin, J. C. Burant, J. M. Millam, S. S. Iyengar, J. Tomasi, V. Barone, B. Mennucci, M. Cossi, G. Scalmani, N. Rega, G. A. Petersson, H. Nakatsuji, M. Hada, M. Ehara, K. Toyota, R. Fukuda, J. Hasegawa, M. Ishida, T. Nakajima, Y. Honda, O. Kitao, H. Nakai, M. Klene, X. Li, J. E. Knox, H. P. Hratchian, J. B. Cross, C. Adamo, J. Jaramillo, R. Gomperts, R. E. Stratmann, O. Yazyev, A. J. Austin, R. Cammi, C. Pomelli, J. W. Ochterski, P. Y. Ayala, K. Morokuma, G. A. Voth, P. Salvador, J. J. Dannenberg, V. G. Zakrzewski, S. Dapprich, A. D. Daniels, M. C. Strain, O. Farkas, D. K. Malick, A. D. Rabuck, K. Raghavachari, J. B. Foresman, J. V. Ortiz, Q. Cui, A. G. Baboul, S. Clifford, J. Cioslowski, B. B. Stefanov, G. Liu, A. Liashenko, P. Piskorz, I. Komaromi, R. L. Martin, D. J. Fox, T. Keith, M. A. Al-Laham, C. Y. Peng, A. Nanayakkara, M. Challacombe, P. M. W. Gill, B. Johnson, W. Chen, M. W. Wong, C. Gonzalez, J. A. Pople, Gaussian, Inc., Wallingford CT, 2004.

[24] a) M. Kohout, Int. J. Quantum Chem. 2004, 97, 651; b) M. Kohout, F. R. Wagner, Y. Grin, Int. J. Quantum Chem. 2006, 106, 1499.

[25] M. Kohout, program DGrid, version 4.2, Dresden, Germany 2007.

[26] P. Flükiger, H. P. Lüthi, S. Portmann, J. Weber, Manno, program MOLEKEL 4.3, 2000.

[27] H. von Benda, A. Simon, W. Bauhofer, Z. Anorg. Allg. Chem. 1978, 438,53 .

[28] a) H. Fjellvåg, S. Furuseth, J. Less-Common Met. 1987, 128, 177; b) V. P. Glagoleva, G. S. Zhdanov, Zh. Eksp. Teor. Fiz. SSSR 1954, 26, 337; c) M. Ruck, T. Söhnel, Z. Naturforsch. $B$ 2006, 61, 785 .

[29] M. Ruck, Angew. Chem. 2001, 113, 1222; Angew. Chem. Int. Ed. 2001, 40, 1182.
[30] H. Okamoto in Binary Alloy Phase Diagrams, $2^{\text {nd }}$ edition, (Ed. T. B. Massalski), ASM International Materials Park, Ohio, 1990, p. 772.

[31] a) M. Ruck, V. Dubenskyy, T. Söhnel, Z. Anorg. Allg. Chem. 2004, 630, 2458; b) B. Wahl, M. Erbe, A. Gerisch, L. Kloo, M. Ruck, Z. Anorg. Allg. Chem. 2009, 635, in press.

[32] a) Yu. Grin, U. Wedig, H. G. von Schnering, Angew. Chem. 1995, 107, 1318; Angew. Chem. Int. Ed. 1995, 34, 1204; b) Q. F. Gu, G. Krauss, Yu. Grin, W. Steurer, J. Solid State Chem. 2007, 180, 940 .

[33] A. N. Kuznetsov, L. Kloo, M. Lindsjö, J. Rosdahl, H. Stoll, Chem. Eur. J. 2001, 7, 2821.

Received: ((will be filled in by the editorial staff)) Published online: ((will be filled in by the editorial staff)) 

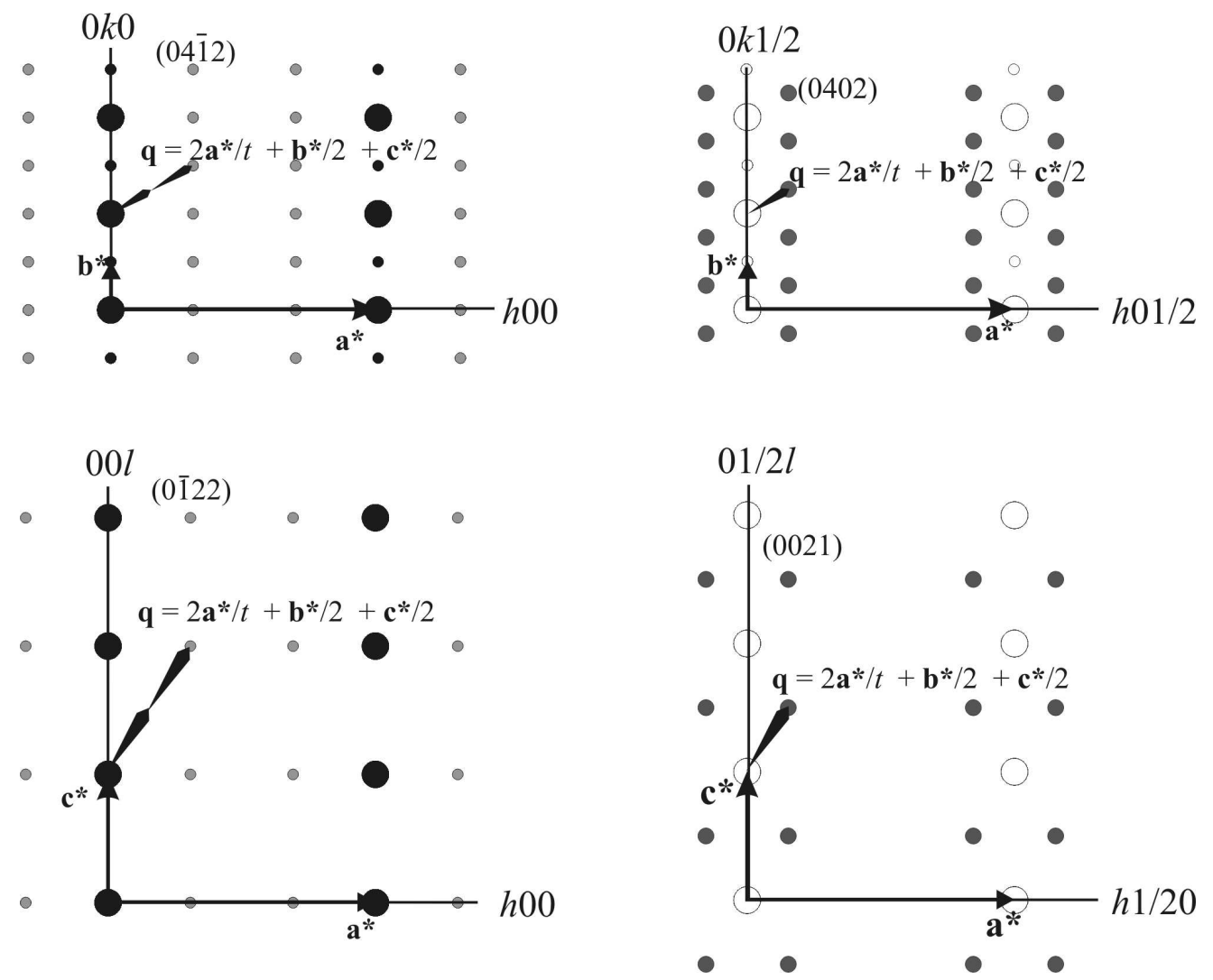

Figure 1. Schematic diffraction pattern of the layers $h k 0 m, h k^{1 / 2} m, h 0 / m$ and $h 1 / 2 / m$ including the chosen q-vector. Main reflections are represented in black, $1^{\text {st }}$ order satellites in dark gray, and $2^{\text {nd }}$ order satellites in light gray. Empty circles in intermediate layers correspond to the position of main reflections.

$84 \times 69 \mathrm{~mm}(600 \times 600 \mathrm{DPI})$ 


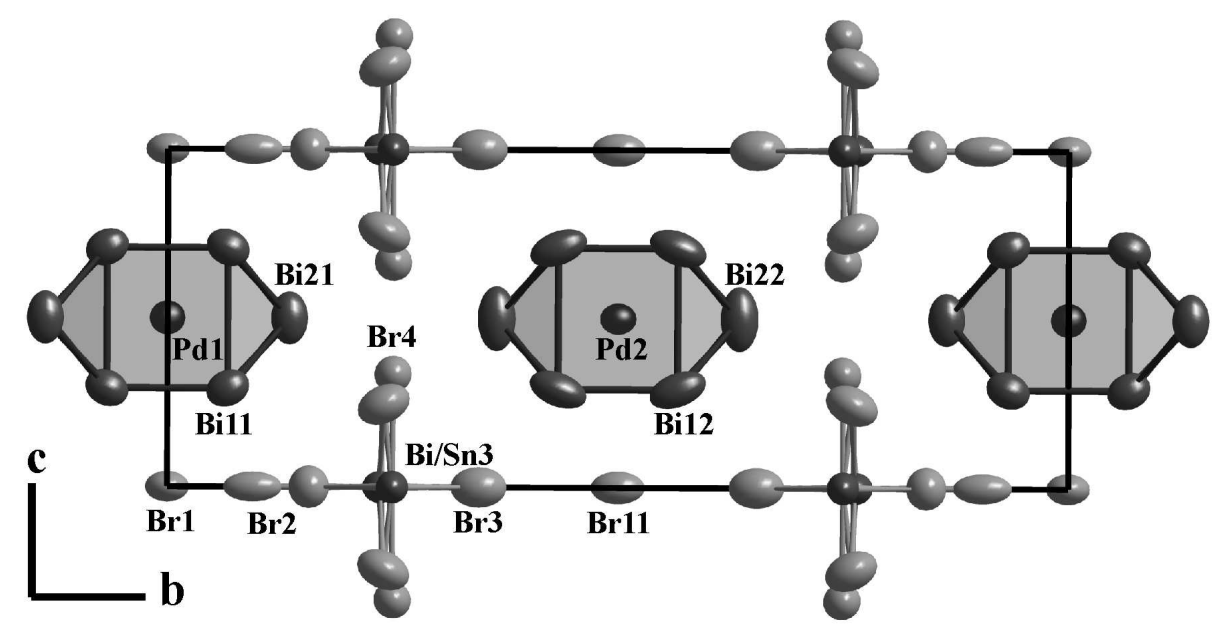

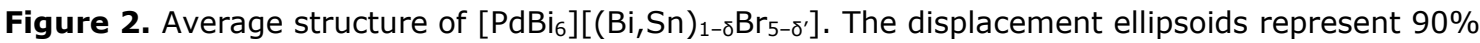
probability at 293(2) K. As in the following figures. Pd atoms are represented in black, Bi atoms in dark gray, and $\mathrm{Br}$ atoms medium gray. $82 \times 41 \mathrm{~mm}(600 \times 600 \mathrm{DPI})$ 


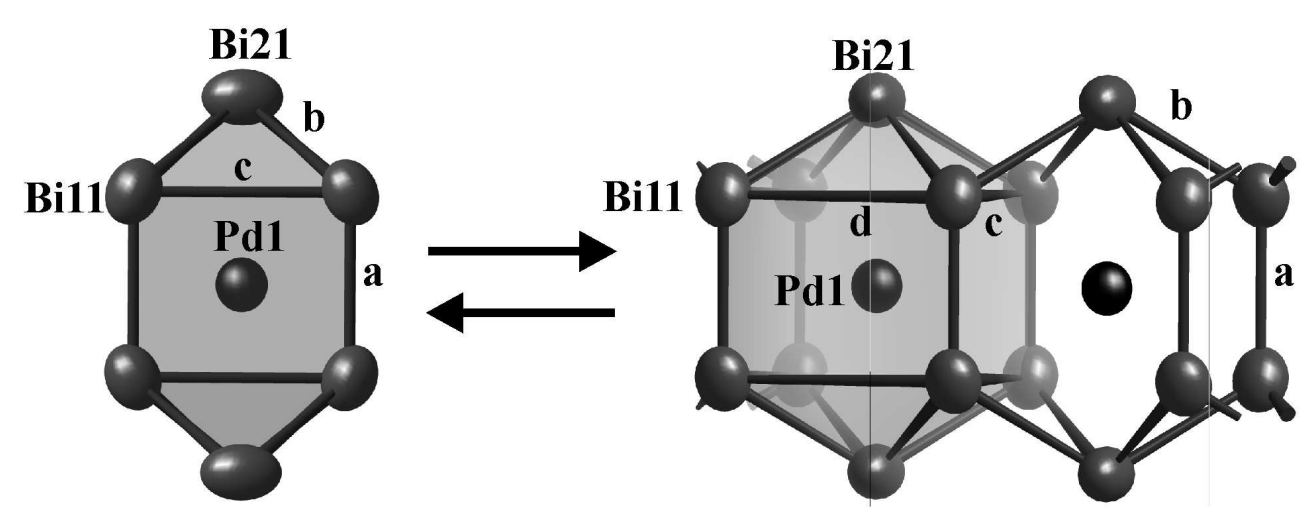

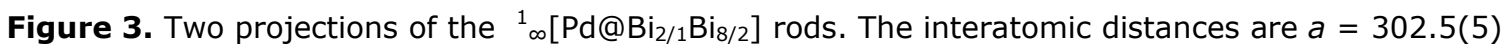
$\mathrm{pm}, b=311.5(5) \mathrm{pm}, c=355(1) \mathrm{pm}$, and $d=408(1) \mathrm{pm}$. The standard deviations given in parentheses are average values. $83 \times 33 \mathrm{~mm}(600 \times 600 \mathrm{DPI})$ 


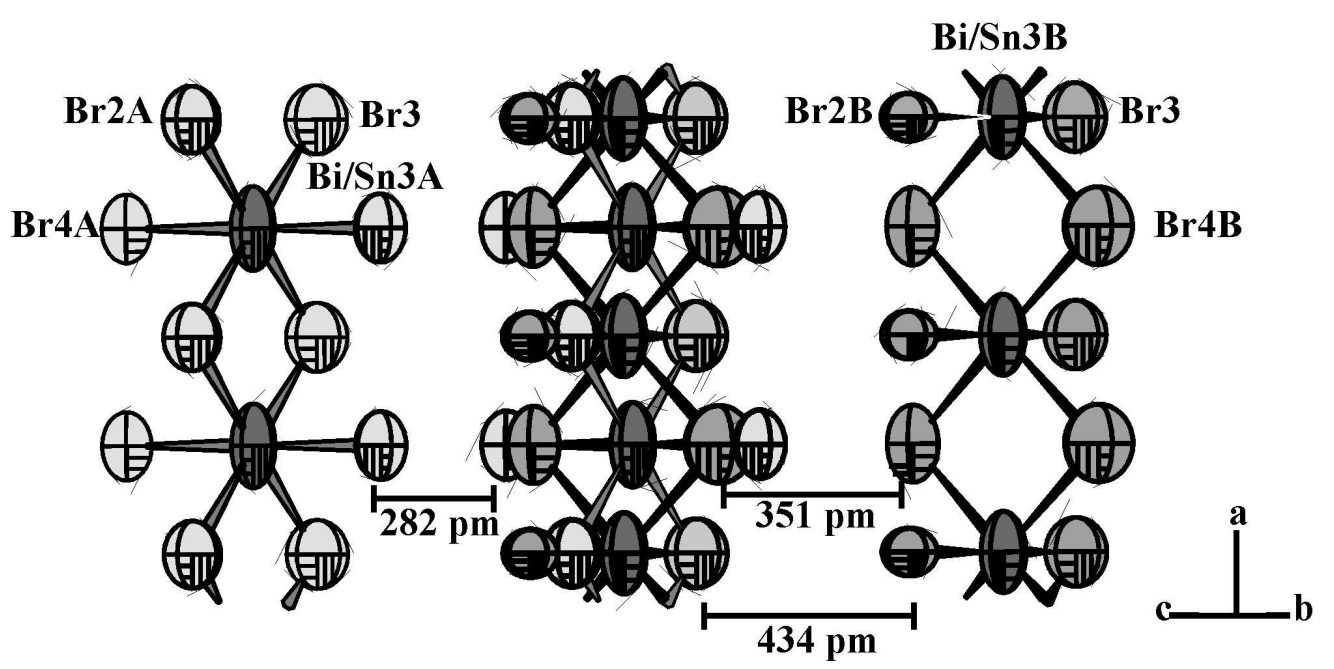

Figure 4. Deconvolution of the disorder in the bromidometallate part of the average structure (center) into two differently oriented ${ }^{1}{ }_{\infty}\left[\mathrm{MBr}_{2 / 1} \mathrm{Br}_{4 / 2}\right]$ chains (left, right), that can be mapped on each other by a local $4_{2}$ screw rotation along [100]. $84 \times 41 \mathrm{~mm}(600 \times 600 \mathrm{DPI})$ 

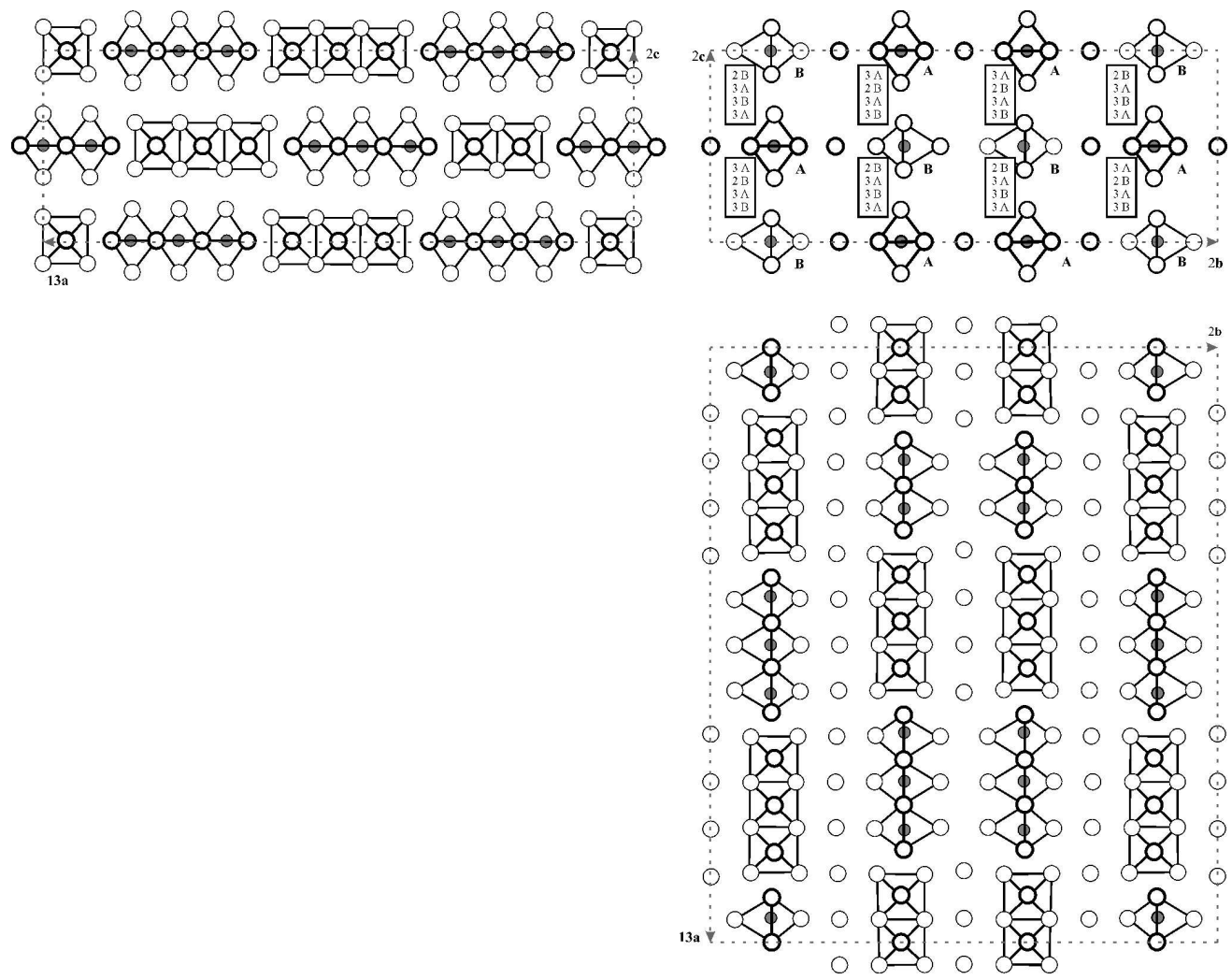

Figure 5. The ordered anionic structure of $\left[\mathrm{PdBi}_{6}\right]\left[(\mathrm{Bi}, \mathrm{Sn})_{1-\delta} \mathrm{Br}_{\left.5-\delta^{\prime}\right]}\right.$ of the modulation variant (1) in the supercell with $a^{\prime}=13 a$ and $b^{\prime}=2 b$ and $c^{\prime}=2 c$ (space group Pmmm). The upper right side represents a section of the modulated structure around $x=0$. In the boxes, the lengths and the orientations of the concatenated octahedra are indicated. Below the layer at $z=0$, and on the left hand side the layer at $y=1 / 8$ are shown. $173 \times 137 \mathrm{~mm}(600 \times 600 \mathrm{DPI})$ 
Figure 6. The electron density distributions around the atoms $M 3 B$ in $x_{2}-x_{4}$ of the modulation variant (1) derived from the diffraction pattern including the superstructure reflections. The contour lines symbolize steps within $20 \mathrm{e}^{-} / 10^{6} \mathrm{pm}^{3}$. The bold lines represent the fit of the atomic positions according to the introduced discontinuous and continuous functions. This section underlines the differences in the ordering of the isolated bromine atoms $\mathrm{Br} 1$ and $\mathrm{Br} 11$. $84 \times 26 \mathrm{~mm}(600 \times 600 \mathrm{DPI})$ 

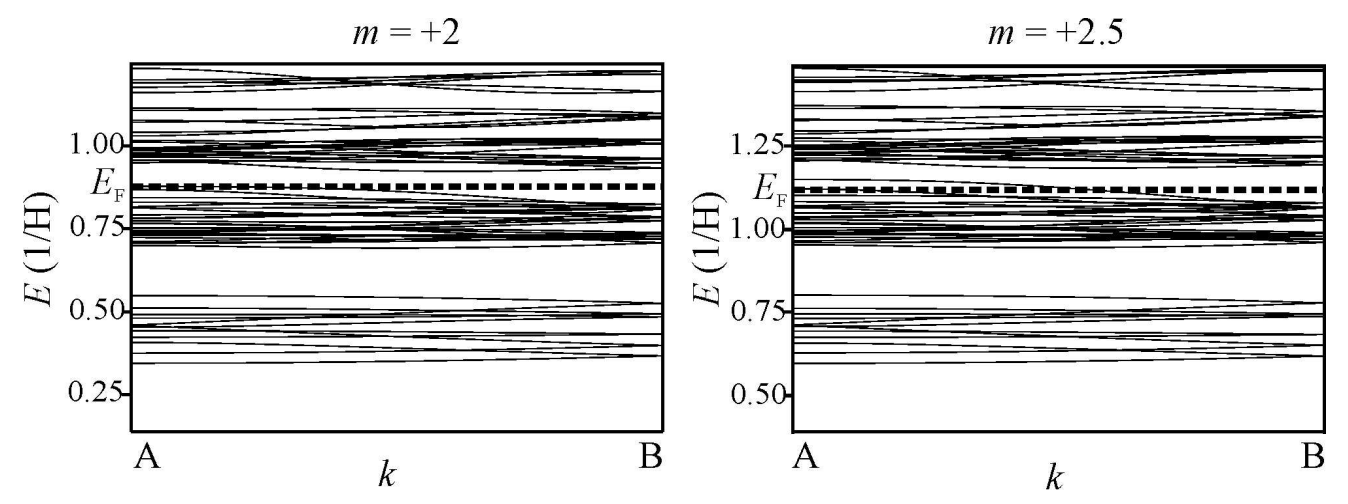

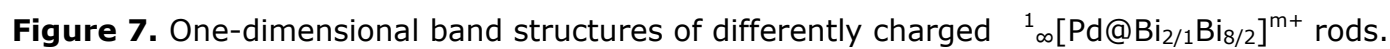
$84 \times 30 \mathrm{~mm}(600 \times 600 \mathrm{DPI})$ 


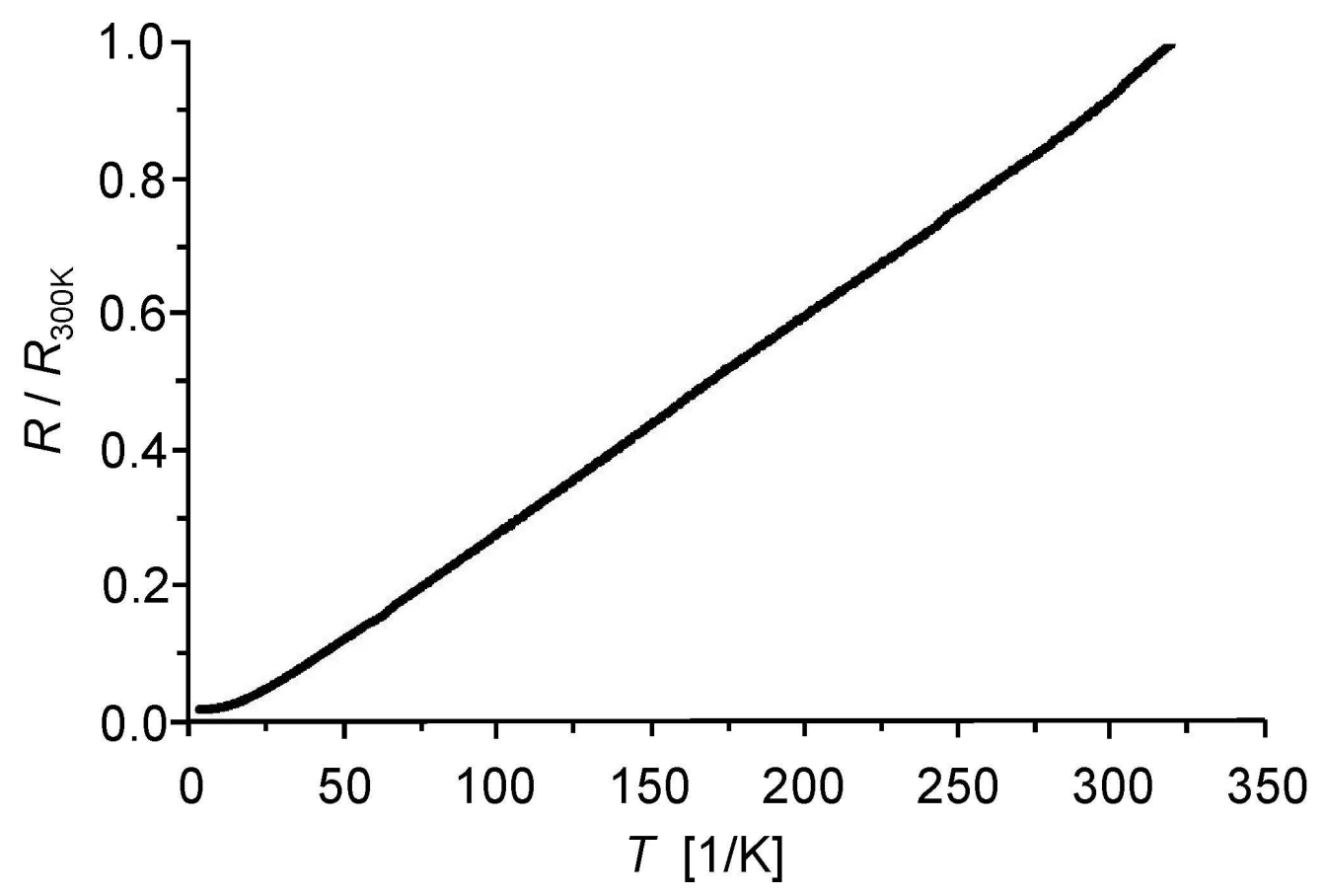

Figure 8. Temperature dependence of the electric resistance along [100] of a single crystal of $\left[\mathrm{PdBi}_{6}\right]\left[(\mathrm{Bi}, \mathrm{Sn})_{1-\delta} \mathrm{Br}_{5-\delta^{\prime}}\right]$. $84 \times 56 \mathrm{~mm}(600 \times 600 \mathrm{DPI})$ 


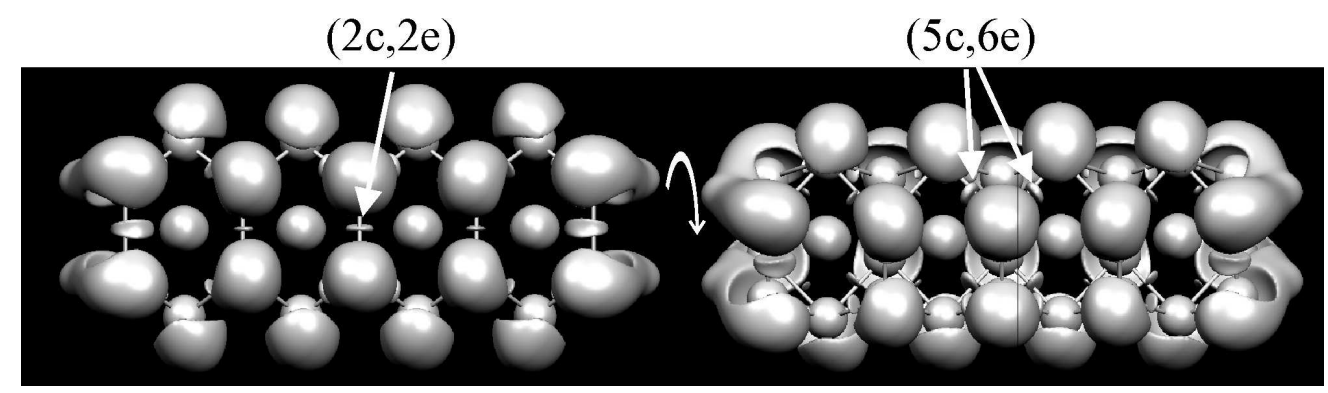

Figure 9. Two views of the ELI-D $(\eta=1.44)$ of an optimized cluster tetramer $\left[\mathrm{Pd}_{4} \mathrm{Bi}_{28}\right]^{8+}$. The attractors between $\mathrm{Bi}$ atoms can be interpreted as $(2 \mathrm{c}, 2 \mathrm{e})$-bonds on the short edges of the cube and $(5 \mathrm{c}, 6 \mathrm{e})$-bonds in the $\mathrm{Bi}^{5+}$ caps. $84 \times 24 \mathrm{~mm}(600 \times 600$ DPI $)$ 

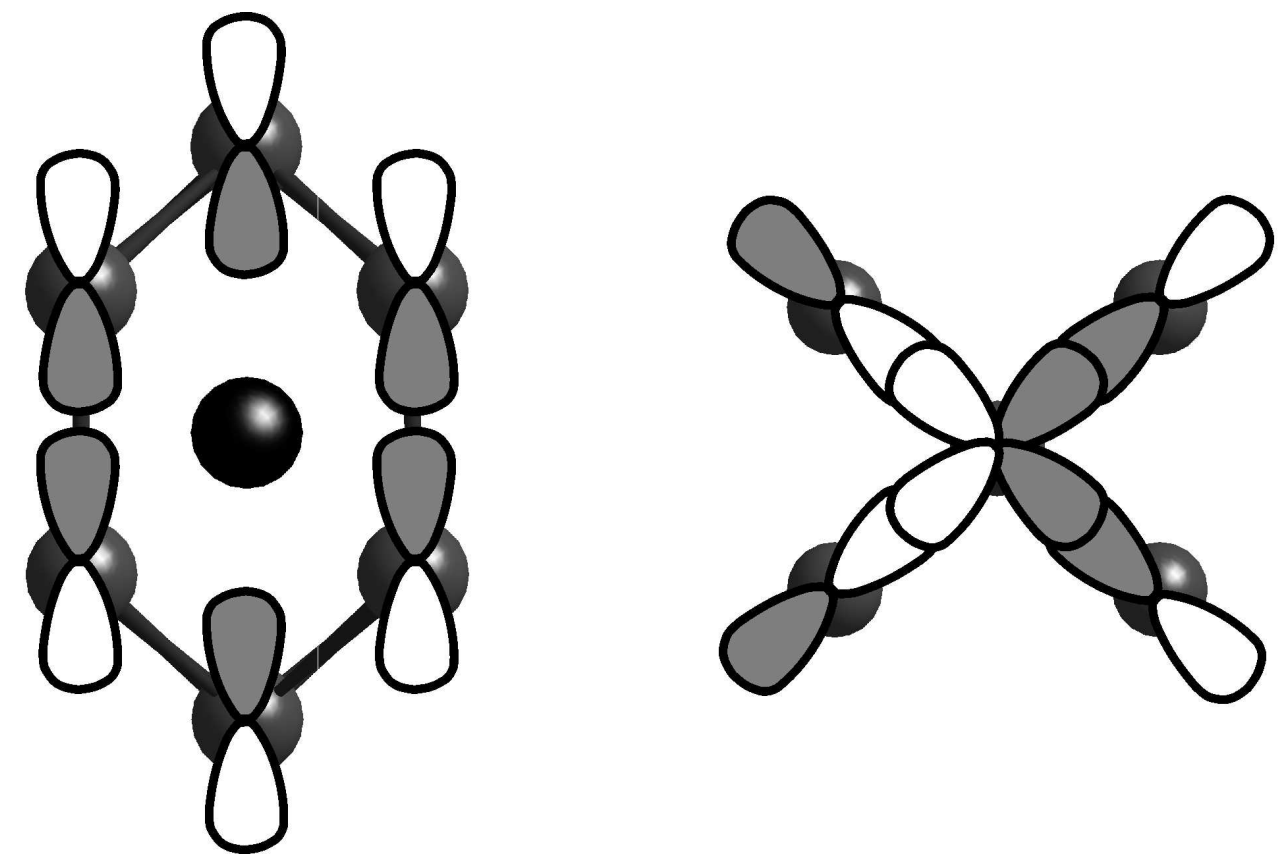

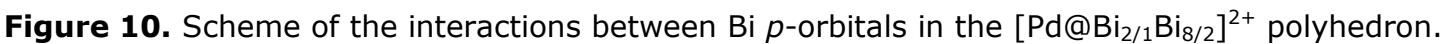
Left: $(2 c, 2 e)$ bonds along the four short edges of the cube, and empty $p_{\mathrm{z}}$-orbitals of $\mathrm{Bi}^{+}$in the apical positions. Right: Top view of $\mathrm{Bi}^{5+}$ cap with six $p_{\mathrm{x}}$ and $p_{\mathrm{y}}$ orbitals, each filled with one electron, that form the $(5 c, 6 e)$ bond. $83 \times 54 \mathrm{~mm}(600 \times 600 \mathrm{DPI})$ 